\title{
Differentiating Bullish From Bearish Factors In The Arbitrage Pricing Theory
}

Joseph M. Cheng, Ithaca College, USA

\begin{abstract}
This is a teaching note on a proposed approach that will correct a common flaw in the way the return-generating process within the APT framework is illustrated in textbooks. The problem can be resolved by dichotomizing the risk factors into two kinds. Based on this approach, the author eliminated the main source of confusion and developed an alternative way to teaching this important financial theory in a comprehensive and intuitive manner.
\end{abstract}

Keywords: Arbitrage Pricing Theory, APT

\section{INTRODUCTION}

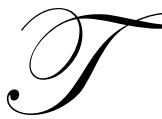

he APT is one of the most important asset pricing theories taught in finance courses, second only to the Capital Asset Pricing Model. The APT is superior to CAPM in many ways because it separates the risk factors, whereas CAPM combined all of the risk factors into a single market beta. However, students often have difficulty in understanding fully the concepts in the APT, especially the one regarding the relationship between the macro- factors and the returns of assets in the APT. While the APT per se is not a difficult theory to comprehend, the way it is illustrated in textbooks may have caused much student confusion over the return-generating process within the APT framework.

I noticed that a common error of exposition occurred in most textbooks that I have examined. The equation for the actual return of an asset is often given as:

$\mathrm{R}=\mathrm{E}(\mathrm{r})+\mathrm{b}_{1}\left(\mathrm{~F}_{1}-\mathrm{EF}_{1}\right)+\mathrm{b}_{2}\left(\mathrm{~F}_{2}-\mathrm{EF}_{2}\right)+\ldots . \mathrm{b}_{\mathrm{n}}\left(\mathrm{F}_{\mathrm{n}}-\mathrm{EF}_{\mathrm{n}}\right)+\mathrm{e}$

where $\mathrm{R}$ represents the actual return of the stock, $\mathrm{E}(\mathrm{r})$ represents the expected return,

$\mathrm{F}$ represents the actual value for the macro-factor index, and $\mathrm{EF}$ represents the expected value for the macro-factor index. The term F- EF measures how much the actual value deviates from what has been previously expected, which is often referred to as the "surprise" term. The four factors identified by Chen, Roll, and Ross were:

1. Growth rate in industrial production

2. Inflation rate

3. Spread between long-term and short-term interest rates

4. Spread between low-grade and high-grade bonds.

$\mathrm{b}$ represents the beta value, which measures the degree of the stock's sensitivities to the respective factor surprise.

The larger the beta, the greater would be the effect of the surprise on the actual return. Thus, beta is a measure for the security's factor risk. The expected or required return of a security should commensurate with factor risks, which are measured by the beta values.

e represents unsystematic return due to unsystematic risk.

$\mathrm{E}(\mathrm{r})=\mathrm{rf}+\mathrm{b}_{1} \mathrm{PREM}_{1}+\mathrm{b}_{2} \mathrm{PREM}_{2}+\ldots$ bn PREMn 
where

$\mathrm{E}(\mathrm{r})$ represents the expected return,

rf represents the risk free rate,

$\mathrm{PREM}_{1}$ represents the risk premium for the first factor, which is calculated by taking the difference between the expected return of the first factor and the risk free rate. PREM may be interpreted as the amount of compensation for bearing one unit of risk or one unit of sensitivity to the respective factor. The value of PREMs' are same for all securities since they are based on the common macro-factor, whereas beta value for each security vary since different security may have different sensitivities to the respective factor.

As one can see from Equation (2), the higher the risk premium for the macro factor $\left(\mathrm{PREM}_{1}\right)$, the higher must be the expected or required return.

Equation (1) is the actual return equation and (2) is the required return equation. These two equations are the standard equations used for illustrating the APT in all textbooks. Unfortunately, this model is often poorly illustrated. The exposition problem has caused much student confusion over the return-generating process within the APT framework. The illustrations often lead to inconsistency between the returns generated by the actual return equation and that by the required return equation. To illustrate the common exposition problem, let me use interest rate as an example for one of the macro-factor indexes. If interest rate turns out to be higher than expected, then the surprise term (F-EF) for the interest rate factor would be positive. And when one multiplies the positive surprise term in (1) by the interest rate beta, which is also positive, one would obtain a positive product that yields a higher return in Equation (1). Obviously, this is a contradiction to financial theory. Return of assets should be inversely related to interest rate and that higher interest rate should yield a lower return.

The problem here is that a positive value for the surprise term may not necessarily be positive (favorable) for stock return, but this is how many textbooks illustrate the APT concept. However, this often goes unnoticed because the illustrations (Equation (1) and (2)) seldom are followed through by an actual numerical example of the effect of the surprise on the actual return. For those that do follow through with a numerical example showing how the surprise term affects return, the inconsistency then becomes transparent.

For example, in a recently published finance textbook, the return-generating process is illustrated by an numerical example. The factor used to illustrate the return-generating process in this case was inflation. Assume that stocks A and B have the same risk in all factors except inflation. Company A(aggressive) has an inflation beta value of 2 and Company $\mathrm{C}$ (conservative) has an inflation beta of .5. Suppose the market expected inflation to be $10 \%$, but the actual inflation that was announced turned out to be $15 \%$; thus, $\mathrm{F}-\mathrm{E}(\mathrm{F})=15 \%-10 \%=5 \%$.

Assume the expected returns, if there are no surprises, for $\mathrm{A}$ and $\mathrm{C}$ are $25 \%$ and $15 \%$, respectively. Then the change in return due to surprise in inflation can be computed as shown in Table 1:

Table 1: Change in Return due to Surprise in Inflation

\begin{tabular}{|l|c|c|c|}
\hline \multicolumn{1}{|c|}{ Company } & Expected return with No Surprise & Change in Return due to Surprise in Inflation & Actual Return \\
\hline Conservative & $15 \%$ & $\mathrm{~B}[\mathrm{I}-\mathrm{E}(\mathrm{I})]=.5(5 \%)=2.5 \%$ & $17.5 \%$ \\
\hline Aggressive & $25 \%$ & $\mathrm{~B}[\mathrm{I}-\mathrm{E}(\mathrm{I})]=2(5 \%)=10 \%$ & $35 \%$ \\
\hline
\end{tabular}

Assume there are no surprises in other factors or excess return due to unsystematic risks. Then actual return can be calculated by adding change in return to expected return, as done in Table 1.

As can be seen from the above example, the actual return turned out to be higher than expected. This is contrary to the financial theory that stocks should be adversely affected by high inflation rates. The stock market tends to react negatively to CPI announcement that suggested inflation is higher than expected by the Commerce Department. Furthermore, the aggressive firm should suffer a greater setback in the face of higher inflation, but its 
actual return calculated was higher than that of the conservative firm. This also is inconsistent with financial theory. The same inconsistency can be found if the index above is interest rate or bond risk premium instead of inflation rate.

One might attempt to reconcile this contradiction by making the inflation beta negative so that the product of the beta and the positive surprise term for the inflation rate would be negative. The problem with this approach is that a negative inflation rate beta contradicts the standard equation (2) that securities with high inflation sensitivity should be compensated with higher (not lower) expected return; thus, making inflation rate beta negative will not do.

\section{RESTRUCTURING THE EQUATION}

Essentially, the problem in textbook illustrations of APT lies in the fact that no distinction is being made between bullish and bearish factors or between favorable and unfavorable surprises in Equation (1). When the actual value of factor index exceeds the expected value index, the surprise term (as measured by F-EF) would automatically be positive, thus leading to higher return. However, this is not correct if the index that has risen happens to be an adverse or bearish index. For instance, as we have noted, a rise in the value of an adverse index, such as inflation rate, would yield a surprise term with a positive value in (1) and thus results in higher return for the asset, even though the effect is in fact unfavorable.

In light of this problem, I propose to specify the return in terms of bullish and bearish macro-factors:

$\mathrm{R}=\mathrm{E}(\mathrm{r})+$ bi FBULLi - bj FBEARj $+\mathrm{e}$

where

FBULLi represents the surprise term (F-EF) for bullish factor i,

FBEARj represents the surprise term (F-EF) for bearish factor $\mathrm{j}$.

Bullish factors are those that tend to boost market return, such as real GDP growth, whereas bearish factors are those macro-factors that tend to depress market return, such as inflation or interest rate. The surprise or difference term is always measured by F-EF for both bullish and bearish factors. A positive surprise term for a bullish factor or a negative surprise term for a bearish factor is favorable surprise which drives returns higher, whereas a positive surprise term for a bearish factors or a negative surprise term for bullish factors is unfavorable surprise which causes returns to be lower.

The application of the above equation can be illustrated by using the same problem as in Table 1. Since higher inflation rate leads to lower market return, it is considered a bearish factor. If the actual inflation rate exceeds the level expected, the surprise term would be positive. When such positive surprise term for the bearish factor is multiplied by beta, a positive product is generated. And because this product is being subtracted before arriving at the return in (3), the positive value in the surprise term reduces the return of the stock and is thus correctly treated as an unfavorable surprise. in Table 2.

For example, using the Bearish Factor Approach, we can modify the return calculation in Table 1 as shown

Table 2: Change in Return using Bearish Factor Approach

\begin{tabular}{|l|c|c|c|}
\hline \multicolumn{1}{|c|}{ Company } & Exp return with No Surprise & Change in Return due to Surprise in Inflation & Actual Return \\
\hline Conservative & $15 \%$ & $-\mathrm{B}[\mathrm{I}-\mathrm{E}(\mathrm{I})]=-.5(5 \%)=-2.5 \%$ & $12.5 \%$ \\
\hline Aggressive & $25 \%$ & $-\mathrm{B}[\mathrm{I}-\mathrm{E}(\mathrm{I})]=-2(5 \%)=-10 \%$ & $15 \%$ \\
\hline
\end{tabular}

Since inflation surprise is regarded as a bearish factor, the change in return due to surprise in inflation is negative (rather than positive). Actual return is derived by adding the change to the expected return, as done in 
Table 2. The calculated actual return is lower than the expected return, which is consistent with financial theory in that stocks are adversely affected by higher inflation rate.

The surprise term for a bullish factor would be treated similarly. For example, the industrial production or GDP growth is considered a bullish factor because a high value of this index is favorable for stocks. If actual industrial production exceeds the level previously expected, then BULLF would be positive. Numerically, if actual production growth is $6 \%$ and expected is only $5 \%$, then BULLF would be $+1 \%$. Substituting this value in Equation (3) would yield a higher return, which is also consistent with financial theory. Furthermore, there is consistency between the returns generated by the actual return equation and that by the required return equation.

Finally, it is possible, though rare, for a stock to have a negative beta for a particular factor risk. For example, stocks for value stores may have a negative beta for the GDP risk factor. When GDP falls, people might shop more in such stores. This does not change the fact that GDP is a bullish factor. The only thing that students need to be aware is that the beta for this stock is negative with respect to this particular bullish factor. Plugging in the negative value for the GDP beta for the stock in the required return equation will generate the appropriate required return for this stock. Thus, the dichotomy approach in distinguishing factors between bullish and bearish works consistently in all cases. This proposed approach of teaching APT will facilitate student understanding of an important financial theory which is currently not well-understood.

The four factors identified by Chen, Roll, and Ross can be classified as follows:

Factors

- Unexpected change in industrial output

- Unexpected change in inflation

- Unexpected change in the yield spread between long term and short term Treasury bonds

- Unexpected change in the bond risk premium
Type

Bullish

Bearish

Bearish

Bearish

\section{CONCLUSION}

While the fundamental concept underlying the APT Model is sound, the conventional approach in illustrating the return-generating process within the APT frameworks needs to be improved and modified. The confusion over the return-generating process can be eliminated by dichotomizing the macro-factors into two types bullish and bearish. This approach ensures the integrity of the model and maintains consistency between the theory and application of the APT. The way the proposed equation (3) is structured makes the illustration of the risk factors and the assets' sensitivity to risk much clearer. I have applied this teaching approach in my class with impressive results. It is truly gratifying to see that students understand and appreciate the APT in a way they never have before.

\section{AUTHOR INFORMATION}

Joseph Cheng is associate professor of finance at Ithaca College where he has been teaching for 25 years. His research interest includes option pricing, optimal capital structure, and integrating biblical perspective to finance.

\section{REFERENCES}

1. Chen, N., R. Roll, and S. A. Ross. "Economic Forces and the Stock Market." Journal of Business, July 1986, 383-493

2. Dybvig, P. H., and Ross, S. 1985. "Approximate Factor Structures: Interpretations and Implications for Empirical Tests,” Vol. 40 (1985), pp. 1367-1373

3. $\quad$ Ross, S.A. "The Arbitrage Theory of Capital Asset Pricing," Journal of Economic Theory, Vol. 13 (Dec 1976), 341-360.

4. $\quad$ Ross, S.A. "Return, Risk, and Arbitrage," in Risk and Return in Finance, eds., I. Friend and J.L. Bicksler. Cambridge, Mass.: Ballinger, 1977 